\title{
GC-MS Identification of Stem Extract of Sida acuta (Burm.f)
}

\author{
T. J. Nalini ${ }^{1 *}$, E. Keshamma ${ }^{2}$, H. N. Ramesh Babu ${ }^{3}$, N. Rajeshwari ${ }^{3}$ and B. T. Sridhar ${ }^{4}$ \\ ${ }^{1}$ Department of Botany, Jnana Sahyadri, Kuvempu University, Shankaraghatta, \\ Shivamogga, Karnataka, India \\ ${ }^{2}$ Department of Biochemistry, Maharani Cluster University, Palace Road, \\ Bengaluru, Karnataka, India \\ ${ }^{3}$ Department of Botany and Seed Technology, Sahyadri Science College, Kuvempu University, \\ Shivamogga, Karnataka, India \\ ${ }^{4}$ Department of Chemistry, Maharani Cluster University, Palace Road, \\ Bengaluru, Karnataka, India \\ *Corresponding author
}

\section{A B S T R A C T}

\section{Keywords}

Sida acuta, Stem, GC-MS,

Antimicrobial, Antifungal, Antiinflammatory

\section{Article Info}

\section{Accepted:} 14 April 2021 Available Online: 10 May 2021
Extracts of Sida acuta can be effectively employed as antimicrobial agents specifically antifungal to control growth and colonization on commercially important plants like Sorghum species. Furthermore, stem part of Sida acuta plant has less studied and hence, it is important to isolate phytoactives from stem extract of Sida acuta. Hence, the present study was designed to conduct with main objective to determine bioactive components of aqueous (aq.) stem extract of Sida acuta by GC-MS analysis. The fresh stem parts of Sida acuta collected was subjected aqueous extraction by successive extraction with water. In the present study we identified 9, 12,15-Octadecatrienoic acid, ethylester, (Z, Z, Z), gamma-Sitpsterol, 1-(+)-Ascorbicacid2, 6-dihexadecanoate, 9, 12Octadecadienoicacid(Z, Z), 4-Hydroxy-2-methylacetophenone, 1, 3-Propanediol, 2(hydroxymethyl)-2-nitro, Stigmasterol and Trilinolein as predominant compounds present in the aq. stem extract of Sida acuta through GC-MS analysis and characterization. In conclusion, this is the preliminary study wherein we identified eleven bioactive compounds in aq. stem extract of Sida acuta and hence, further invitro and in-vivo research investigations are recommended to evaluate the pharmacological activities of prevailing compounds identified in aq. stem extract of Sida acuta.

\section{Introduction}

Since the beginning of human civilization, medicinal plants have been used by mankind for their nutritional and therapeutic values. Nature has been a source of medicinal agents for thousands of years and an impressive number of modern drugs have been isolated 
from natural sources. Many of these isolations were based on the uses of these agents in traditional medicine. Sida acuta Burm. f (Malvaceae) is one of those plants currently used by indigenous people for the management of some health problems. This plant is an erect, branched small perennial herb or small shrub of about $1.5 \mathrm{~m}$ height (Mohiden et al., 2002). The bark is smooth, greenish, the root is thin, long, cylindrical and very rough; leaves are lanceolate, nearly glabrous, peduncles equal to the petioles, the flowers are yellow, solitary or in pairs; seeds are smooth and black (Gamble et al., 1935; Sreedevi et al., 2009). It grows abundantly on cultivated fields, waste areas and roadsides in Cameroon, where it is called "sengh" in the Western part of the country. It common name is Sida. Once the plant becomes established, it is very competitive, holding and denying sites to other plants. The plant can be propagated both by seed and stem cuttings. All parts of this tree, including leaves, bark, root, seeds and flower are used in folkloric medicine (Tcheghebe et al., 2017).

All parts of the Sida acuta are used for therapeutic purposes, but the leaves are the most frequently request. Leaves are considered to possess demulcent, diuretic, anthelmintic, wound healing properties and are used to treat rheumatic affections (Tcheghebe et al., 2017). The leaves decoction is used to treat abdominal pain, hemorrhoids, azoospermia and oligospermia (Mshana et al., 2000). The leaf juice is also used in India for vomiting and gastric disorders(Ramachandra and Nair 1981). The roots of the Sida species are considered excellent adaptogenic and immunomodulator, general nutritive tonic and prolonged life; useful in tuberculosis and in diseases associated with injury, heart diseases, cough and respiratory diseases (Nadkarni et al., 1976). Root is also claimed to possess aphrodisiac, antirheumatic, stomachic, diaphoretic, diuretic, antipyretic and wound healing properties (Mohiden et al., 2002). The root extract is taken in the case of leucorrhoea (Saraswathy et al., 1976), breathing problems and cough(Silija et al., 2008). In Papua New Guinea, the fresh root is chewed for the treatment of dysentery (Hodlsworth 1974). In Indian traditional medicine, the root of Sida acuta is extensively used as a stomachic, diaphoretic and antipyretic. It is regarded as cooling, astringent, tonic and useful in treating nervous and urinary diseases and also disorders of the blood, bile and liver (Khare et al., 2002), while the hot water extract of the dried entire plant is administered orally as a febrifuge, an abortifacient and a diuretic (Kholkute et al., 1978). It is also used to treat gonorrhea, elephantiasis, ulcers and is claimed to have aphrodisiac properties. The juice of the root is applied to wounds. The whole plant extract is often assumed to treat diseases such as fever, headache, skin diseases, diarrhea and dysentery (Ignacimuthu et al., 2006). It is used as diuretic in rheumatic infections, used as a demulcent in gonorrhoea and chronic dysentery (Nadkarni et al., 1976). Sida acuta is an ingredient in Siddha formulation indicates in rheumatism, facial paralysis, pulmonary tuberculosis, sciatica, haemorrhage, spermatorrhoea, leucorrhoea and gonorrhea (Saraswathy et al., 1976).

Sida acuta plant is credited with abortifacient, anthelmintic and antiemetic properties (Jain 1991). In Nicaragua, the decoction of the entire plant is taken orally for asthma, fever, aches, pains, ulcers and as an anti-worm medication; while a decoction of the dried entire plant is taken orally for venereal diseases (Barrett 1994; Coe and Anderson 1996). In Central America, the plant is used to treat asthma, renal inflammation, cold, fever, headache, ulcers and worms (Caceres et al., 1996). In Colombia the whole plant is known to treat snake bites and it lessened the hemorrhagic effect of Bothrops atrox venom (Otero et al., 2000; Trivedi et al., 2013). In 
Cameroon, the whole plant is claimed to possess antiinflammatory, antirheumatic, diaphoretic, febrifuge, sedative, anti-ulcer and anthelmintic properties. A decoction of the whole plant is used for the treatment of fever and rheumatism and to eradicate intestinal worms. The same decoction is also used to treat malaria (Olivier et al., 2016).

Furthermore, In Sorghum (Sorghum bicolour), covered smut (Sphacelotheca sorghi), lead smut (Sphacelotheca sorghi), and long smut (Tolyposporium ehrenbergii) have been reported to be the most destructive pathogens, causing heavy losses in third world countries (Osunlaja 1990). Sorghum has been found to be associated with seed-brone pathogen viz. Fusarium moniliforme which causes seed rot, Gloecercospora sorgi which causes zonate leaf spot, Sphacelotheca sp., which causes smut, Ascochyta sorghina causal agent of rough leaf spot. Fusarium moniliforme is reported to be serious in sorghum as in rice and maize. This pathogen reduces sorghum stands causing stalk rot, top rot and moldy ears. It may depreciate yield to a great extent (Alka et al., 2012). Literature reports evidenced extracts of Sida acuta possess antifungal activites against Candida albicans (Akilandeshwari et al., 2010), Aspergillus nigerand Aspergillus flavus (Ezeabara and Egenti 2018). Hence, extracts of Sida acuta can be effectively employed as antimicrobial agents specifically antifungal to control growth and colonization on commercially important plants like Sorghum species.

Literature survey revealed that stem part of Sida acuta plant has less studied and hence, it is important to isolate phytoactives from stem extract of Sida acuta. The initial steps are extraction and separation of the active phytochemicals from plants before identifying their active ingredients (Karimi and Jaafar 2011). Methods for identifying such compounds should be simple and repeatable. One of the best methods for identifying these compounds is gas chromatography-mass spectrometry (GC-MS), which can isolate and analyze compounds in a single step using a mass detector and available GC-MS libraries (Gomathi et al., 2015). Therefore, the present research investigation was carried out to identify the active molecules present in aq. stem extract of Sida acuta using simple solvent extraction followed by GC-MS analysis.

\section{Materials and Methods}

\section{Plant Material}

The stem part of Sida acuta were collected from natural habitat at Shivamogga District, Karnataka, India. The plant was identified by Dr. H. N. Ramesh Babu, Associate Professor, Department of Botany and Seed Technology, Sahyadri Science College, Kuvempu University, Shivamogga, Karnataka, India.

\section{Extraction Procedure}

The fresh stem parts of Sida acuta collected was subjected aqueous extraction according to method described by Jose and Radhamany. $500 \mathrm{~g}$ of the fresh stem parts of Sida acuta sample was washed to remove the surface pollutants, dried at $40^{\circ} \mathrm{C}$ until complete dry and powdered. These samples were subjected for the successive extraction with water. $25 \mathrm{~g}$ of powdered sample was filled in a Whatmann filter paper and kept inside tumble. $200 \mathrm{ml}$ of the water was added in tumble. The tumble was fit into a round bottom flask containing $700 \mathrm{ml}$ of the solvent and run for 6-8 hours at the temperature based on the boiling point of the respective solvent using Soxhlet apparatus. Later the extract was subjected for the distillation for 2-3 hours. These extracts were kept in hot air over at $60^{\circ} \mathrm{C}$ for drying. The dried extracts thus obtained were used for GCMS analysis and characterization (Jose and Radhamany 2013). 


\section{Gas Chromatography-Mass Spectrometry (GC-MS) Analysis}

\section{Sample preparation}

Sample was grinded with GC grade methanol, centrifuged, the supernatant was collected and injected into the GC-MS system.

\section{GC-MS instrument setup details}

GC-MS analysis was performed using an Agilent make 5977B GC/MSD System. GC/MS system equipped with an TG 5MS silica Capillary column $(30 \mathrm{~m} \times 0.25 \mathrm{~mm} \mathrm{ID})$ $\times \mathrm{MDF}$ composed of $5 \%$ diphenyl/95\% dimethyl polysiloxane with $0.25 \mu \mathrm{m}$ film thickness. For GC/MS detection, an electron ionization system with ionization energy of 70 $\mathrm{eV}$ was used.

The oven temperature was programmed from $80^{\circ} \mathrm{C}$ with a hold of $2 \mathrm{mins}$ and then $200^{\circ} \mathrm{C}$ at $9^{\circ} \mathrm{C} / \mathrm{min}$ and a hold for $4 \mathrm{~min}$ and then to $300^{\circ} \mathrm{C}$ at $10^{\circ} \mathrm{C} / \mathrm{min}$ and a hold for $5 \mathrm{~min}$. Helium was used as carrier gas at flow at the flow rate of $1.5 \mathrm{ml} / \mathrm{min}$. The injector temperature was $250^{\circ} \mathrm{C}$, injection size $1.0 \mu \mathrm{l}$ needle with spitless mode. Injector temperature was $250^{\circ} \mathrm{C}$ and ion source temperature was $230^{\circ} \mathrm{C}$. The interface and MS ion source were maintained at $300^{\circ} \mathrm{C}$ and $230^{\circ} \mathrm{C}$, respectively.

Mass spectra were taken at $70 \mathrm{eV}$; a scan interval of 0.2 seconds and fragments from with a mass scan range of 50-550 amu. Total GC running time was $35 \mathrm{~min}$. The relative percentage amount of each component was calculated by comparing its average peak area to the total areas. Data handling was done using Xcaliber software. The identification of compounds was based on comparison of their mass spectra with those of NIST Libraries. Software adopted to NIST 2014 (2.2.0.0) with AMDIS v.2.72 Version.

\section{Results and Discussion}

GC-MS analyses of the aq.stem extract of Sida acuta led to the identification of 41 components(Figure 1). The 41 peaks identified account for $100 \%$ of the extractand listed along with respective retention time and the percentage of compound in the extract in Table 1.

The GC-MS examinations of the aq.stem extract of Sida acuta prompted the distinguishing proof of 41 compounds. The 41peaks recognized record for $100 \%$ of the extract. Forty-one compounds were detected in the aq. stem extract of Sida acuta. Based on the RT and peak area of individual bioactive compounds, the predominant compounds were 9,12,15-Octadecatrienoic acid, ethylester, (Z,Z,Z)- (14.5\%), gamma-Sitpsterol (12.14\%), 1-(+)- Ascorbicacid 2,6-dihexadecanoate $(11.24 \%), \quad 9,12$-Octadecadienoicacid(Z,Z)(9.65\%), 4-Hydroxy-2-methylacetophenone (6.94\%), 1,3-Propanediol, 2-(hydroxymethyl)2-nitro- $(6.25 \%)$, Stigmasterol $(6.00 \%)$ and Trilinolein $(4.47 \%)$. Their chemical structures were predicted using the mass spectra based on their fragmentation, which generates peaks with different mass-to-charge ratios $(\mathrm{m} / \mathrm{z})$.

For thousands of years, plants and herbs have been a tremendous source of food and medicine. Various parts of Sida acuta have been reported in many studies to be used by indigenous people from tropical countries to manage some health problems. Bioactive constituents such as alkaloids, saponins, coumarins, steroids, tannins, phenolic compounds, cardiac glycosides, sesquiterpene and flavonoids, significantly present in the plant extract of Sida acuta account for its multiple properties and uses in traditional medicine (Tacheghebe et al., 2017). Extracts of Sida acuta can be effectively employed as antimicrobial agents specifically antifungal to control growth and colonization on 
commercially important plants like Sorghum species since literature reports evidenced antifungal activites of Sida acuta extracts (Alka et al., 2012; Akilandeshwari et al., 2010; Ezeabara and Egenti 2018). Moreover, that stem part of Sida acuta plant has less studied. Hence, in the present study we aimed to identify the active molecules present in aq. stem extract of Sida acuta using simple solvent extraction followed by GC-MS analysis.

Many scientific researchers have been carried out in order to determine the chemical composition of Sida acuta. Almost all parts of the plant are concerned by these researches, but leaves and root are the most studied. The phytochemical screening of Sida acuta species revealed the presence of alkaloids such as vasicine, ephedrine and cryptolepine (the main alkaloid in the plant) (Prakash et al., 1981; Karou et al., 2005), saponosides, coumarins, steroids $\quad$ (ecdysterone, $\quad \beta$-sistosterol, stigmaterol, ampesterol), tannins, phenolic compounds (evofolin-A, B-scopoletin, loliolid and 4-ketopinoresinol), polyphenol, sesquiterpene and flavonoids (Konate et al., 2010). In another study, Nwankpa et al., evaluated the phytochemical and micronutrient composition of Sida acuta using standard analytical methods. The phytoconstituents includes tannins, alkaloids, saponins, flavonoids, steroids, terpenoids, and cardiac glycosides. The vitamin composition was thiamin, niacin, ascorbic acid, tocopherol, riboflavin, while mineral composition was found to be calcium, magnesium and zinc, respectively (Nwankpa et al., 2015).

In our study, the predominant compounds identified through GC-MS analysis were 9, 12, 15-Octadecatrienoicacid,ethylester, (Z, Z, Z), gamma-Sitpsterol, 1-(+)-Ascorbicacid2, 6dihexadecanoate, 9, 12-Octadecadienoic acid
(Z, Z), 4-Hydroxy-2-methylacetophenone, 1, 3-Propanediol, 2-(hydroxymethyl)-2-nitro, Stigmasterol and Trilinolein. In the study conducted by Muneeswari et al., the GC-MS analysis observed the presence of 35 different compounds each belonging to different classes such as sterols, flavonoids, terpenes, heterocyclic aromatic compounds, phenols, fatty acids, vitamins, alkaloids and sesquiterpenoids. The results indicate that the ethanolic extract of Sida acuta leaves collected from the Tuticorin District of Tamil Nadu is an effective scavenger of free radicals and has the potential to be used as a natural antioxidant which is attributable to the rich presence of its secondary metabolites (Muneeswari et al., 2019).

Akilandeswari et al., carried out antibacterial and antifungal activity studies of leaf extracts of Sida acuta. Antibacterial and antifungal activity studies of leaf extracts of Sida acuta were carried out. Two common solvents (Chloroform and Ethanol, 95\% each) were used successively for extraction of active principles from the dried powdered leaves. The antimicrobial screening was done with two Gram +ve (Staphylococcus aureus NCIM 2079, Bacillus subtilis NCIM 2063) and two Gram-ve (Escherichia coli NCIM 2065 Pseudomonas aeruginosa NCIM 2036) bacteria and fungi (Candida albicans NCIM 3102, Aspergillus niger NCIM 1054) as test microorganisms. All the three microorganisms were markedly affected by both the extracts under study, with the maximum activity recorded against gram positive Staphylococcus aureus and gram-negative Escherichia coli respectively. These effects were similar to that of commercially available antibiotics under the same laboratory condition (Akilandeshwari et al., 2010). The similar result was previously obtained by Oboh et al., (Obah et al., 2007). 
Table.1 Chemical composition of aq. stem extract of Sida acuta

\begin{tabular}{|c|c|c|c|}
\hline Peak No. & RT & Area $(\%)$ & Name of Compound \\
\hline 1 & 4.727 & 1.55 & N, N-Dimethylglycine \\
\hline 2 & 5.683 & 0.50 & 1,3,5-Triazine-2,4,6-triamine \\
\hline 3 & 6.650 & 0.24 & 4H-Pyran-4-one,2,3-dihydro-3,5-dihydroxy-6-methyl- \\
\hline 4 & 7.672 & 0.41 & Benzofuran,2,3-dihydro- \\
\hline 5 & 9.018 & 6.94 & 4-Hydroxy-2-methylacetophenone \\
\hline 6 & 9.507 & 1.09 & Pyridine,3-(1-methyl-2-pyrrolidinyl)-,(S)- \\
\hline 7 & 10.761 & 6.25 & 1,3-Propanediol, 2-(hydroxymethyl)-2-nitro- \\
\hline 8 & 12.201 & 1.11 & 3',5'-Dimethoxyacetophenone \\
\hline 9 & 12.664 & 2.74 & 3-Deoxy-d-mannoiclactone \\
\hline 10 & 14.201 & 1.49 & 4-((1E)-3-Hydroxy-1-propenyl)-2-methoxyphenol \\
\hline 11 & 15.256 & 0.42 & 3,7,11,15-Tetramethyl-2-hexadecen-1-ol \\
\hline 12 & 15.726 & 0.23 & Syn-Tricyclo[5.1.0.0(2,4)]oct-5-ene,3,3,5,6,8,8-hexamethyl- \\
\hline 13 & 16.110 & 0.29 & Hexadecanoicacid,methylester \\
\hline 14 & 16.471 & 11.24 & 1-(+)-Ascorbicacid2,6-dihexadecanoate \\
\hline 15 & 16.805 & 0.90 & Benzenemethanol,2,5-dimethoxy-,acetate \\
\hline 16 & 17.246 & 0.20 & Z,Z-8,10-Hexadecadien-1-ol \\
\hline 17 & 17.499 & 0.48 & 1-(1-Ethyl-2,3-dimethyl-cyclopent-2-enyl)-ethanone \\
\hline 18 & 17.760 & 0.43 & 9,12-Octadecadienoicacid(Z,Z)-,methyl ester \\
\hline 19 & 17.816 & 0.33 & 9,12,15-Octadecatrienoicacid,ethyl ester, (Z,Z,Z)- \\
\hline 20 & 17.941 & 1.87 & Phytol \\
\hline 21 & 18.131 & 9.65 & 9,12-Octadecadienoicacid(Z,Z)- \\
\hline 22 & 18.184 & 14.5 & 9,12,15-Octadecatrienoicacid,ethylester, (Z,Z,Z)- \\
\hline 23 & 18.371 & 2.93 & Octadecanoicacid \\
\hline 24 & 21.148 & 0.23 & Bacteriochlorophyll-c-stearyl \\
\hline 25 & 21.294 & 2.22 & Hexadecanoicacid,2-hydroxy-1-(hydroxymethyl)ethylester \\
\hline 26 & 21.627 & 0.58 & 1,2-Benzenedicarboxylicacid,mono(2-ethylhexyl)ester \\
\hline 27 & 21.956 & 0.23 & 1H-Phenanthro[9,10-c]pyrazole \\
\hline 28 & 22.684 & 4.47 & Trilinolein \\
\hline 29 & 23.451 & 0.22 & Hexatriacontane \\
\hline 30 & 23.696 & 0.43 & 2,6,10,14,18,22-Tetracosahexaene,2,6,10,15,19,23-hexamethyl-, (all- \\
\hline 31 & 24.142 & 0.71 & Tetrapentacontane \\
\hline 32 & 24.442 & 0.52 & Tetracosamethyl-cyclododecasiloxane \\
\hline 33 & 25.705 & 0.32 & Tetrapentacontane \\
\hline 34 & 26.190 & 1.01 & 26-Nor-5-cholesten-3.beta.-ol-25-one \\
\hline 35 & 27.314 & 2.03 & Ergost-5-en-3-ol, (3.beta.)- \\
\hline 36 & 27.676 & 6.00 & Stigmasterol \\
\hline 37 & 28.385 & 12.14 & gamma.-Sitosterol \\
\hline
\end{tabular}




\begin{tabular}{|c|c|c|c|}
\hline $\mathbf{3 8}$ & 28.949 & 0.43 & $\begin{array}{c}4,4,6 \mathrm{a}, 6 \mathrm{~b}, 8 \mathrm{a}, 11,11,14 \mathrm{~b}-\text { Octamethyl- } \\
\end{array}$ \\
\hline $\mathbf{3 9}$ & 29.394 & 0.44 & $1,4,4 \mathrm{a}, 5,6,6 \mathrm{a}, 6 \mathrm{~b}, 7,8,8 \mathrm{a}, 9,10,11,12,12 \mathrm{a}, 14,14 \mathrm{a}, 14 \mathrm{~b}-\mathrm{oc}$ \\
\hline $\mathbf{4 0}$ & 29.774 & 0.33 & Ergosta-4,22-dien-3-one \\
\hline $\mathbf{4 1}$ & 30.284 & 1.85 & Vitamin E \\
\hline
\end{tabular}

Fig.1 GC-MS spectra of aq. stem extract of Sida acuta

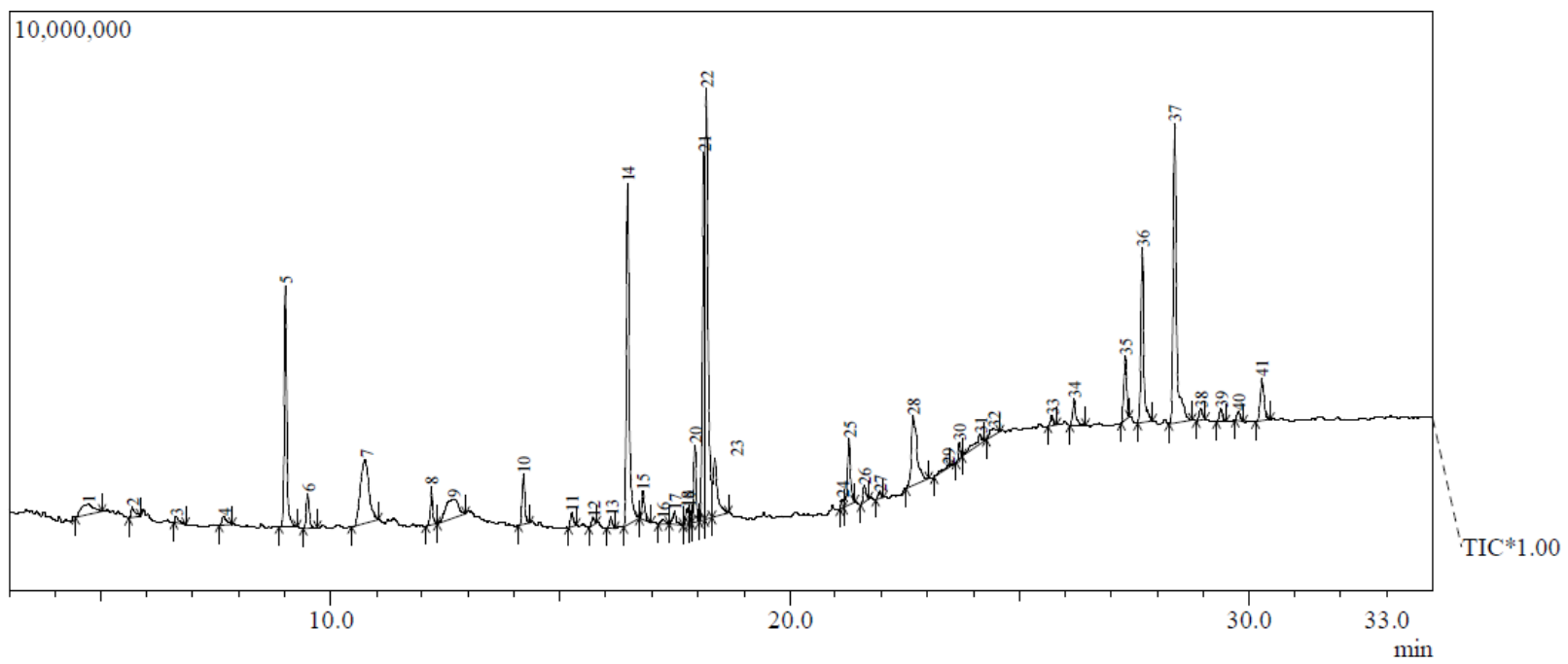

In another study, antimicrobial activity of aqueous and ethanol leaves extracts of Sida acuta against 45clinical isolates of Staphylococccus aureus isolated from nasal cavity of Human Immunodeficiency Virus/Acquired Immuno deficiency Syndrome (HIV/AIDS) patients from University of Nigeria teaching hospital, Enugu, was evaluated using agar well diffusion method(Iroha et al., 2009). The minimum inhibitory concentration (MIC) of the extracts was also determined using agar well diffusion technique and the killing rate of each extract was also determined at different time intervals of 0-90 min. The results of the agar well diffusion study revealed that ethanol extracts produced the highest antimicrobial activity $(86 \%)$, followed by hot water $(61 \%)$ and cold water extracts (48\%). The MIC obtained ranged from $0.9625-1.8125 \mu \mathrm{g} / \mathrm{mL}$ for ethanol extracts, $7.8125-31.25 \mu \mathrm{g} / \mathrm{mL}$ for hot water and $15.625-31.25 \mu \mathrm{g} / \mathrm{mL}$ for cold water extracts. The result of killing rate studies showed that the test organisms were killed within 0-10 min for ethanol and hot water extracts and 5-60 min for cold water extracts. The overall results indicated that Sida acuta extracts have appreciable antimicrobial activity against Staphylococccus aureus isolated from HIV/AIDS patients. In addition to authenticating the folkloric use of Sida acuta in the treatment of common diseases, the finding of these studies highlights the possible usefulness of this plant material in the treatment of opportunistic infections caused by Staphylococccus aureus in HIV/AIDS patients.

Kannan et al., screened cardioactive herbs from Western Ghats of India. The heart beat rate (HBR) and blood flow during systole and diastole were tested in Zebrafish embryos. The methanol extract of Sida acuta led to decrease in the HBR in Zebrafish embryos, which was greater than that caused by Nebivolol (used as reference drug) (Kannan and Vincent 2012). 
Hepatoprotective effects of methanol extract of Sida acuta were obtained against liver damage induced by paracetamol overdose as evident from decreased serum levels of glutamate pyruvate transaminase, glutamate oxaloacetate transaminase, alkaline phosphatase and bilirubin in the Sida acuta treated groups compared to the intoxicated controls(Sreedevi et al., 2009). Akilandeswari et al., reported that wounds contracting ability of the methanol extract of Sida acuta ointment produced significantly greater response in wound types when compared with control.

Furthermore, Akilandeswari et al., reported the significant antiulcer activity against all the three ulcer inducing experimental models, by reducing the ulcer index in those models (Akilandeshwari et al., 2010). The antiulcer activity of ethanol extract of whole plant of Sida acuta was also supported by Malairajan et al., (2006).

Overall, Sida acuta has been scientifically studied for its numerous pharmacological profiles such as antioxidant, antimicrobial, antibacterial, antimalarial, cardiovascular, antiulcer, analgesic, anti-inflammatory, antipyretic, hepatoprotective, hypoglycemic, insecticidal and anticancer. Earlier studies evidenced that a variety of naturally occurring fatty acids was operational in the promotion of ideal health. In addition to its major role in cardioprotection, these fatty acids possessed anti-cancer and free-radical scavenging effects, and hence the extract might be used as a promising natural source of anticancer substance (Arab et al., 2016). The plant-based sterols have been reported to contain various roles in the prevention of human pathologies (Han et al., 2016).

Each year, about $20 \%$ of the sorghum that otherwise would be available for food and feed is lost due to diseases. Seed health plays an important role in the successful cultivation and yield exploitation of a crop species. Healthy seed plays an important role not only for successful cultivation but also for increasing the yields of crops. Seed-borne pathogens of sorghum are responsible for variation in plant morphology and also reducing yield up to 15 to $90 \%$ if untreated seeds are grown in the field.

Several seed-borne pathogens are known to be associated with sorghum seed which are responsible for deteriorating seed quality during storage. Seed stored in humid and warm environments tend to absorb moisture from the surroundings, leading to increased seed moisture content until equilibrium is established. As seed moisture content increases, the rate of deterioration also increases (Jayashree et al., 2019).Therefore, in future studies we planned to evaluate the antifungal activities of phytoactives of Sida acuta against fungal species associated with Kharif Sorghum since literature reports evidenced antifungal activites of Sida acuta extracts (Alka et al., 2012; Akilandeshwari et al., 2010; Ezeabara and Egenti 2018).

To the best of our literature this is the preliminary study wherein we identified 9,12 , 15-Octadecatrienoicacid,ethylester, $(\mathrm{Z}, \mathrm{Z}, \mathrm{Z})$, gamma- Sitpsterol, 1-(+)-Ascorbicacid2, 6dihexadecanoate, 9, 12-Octadecadienoic $\operatorname{acid}(Z, Z), 4-H y d r o x y-2-m e t h y l a c e t o p h e n o n e$, 1, 3-Propanediol, 2-(hydroxymethyl)-2-nitro, Stigmasterol and Trilinolein as predominant compounds present in the aq.stem extract of Sida acuta through GC-MS analysis and characterization.

Hence, further in-vitro and in-vivo research investigations are recommended to evaluate the pharmacological activites especially antifungal activities of compounds identified in aq. stem extract of Sida acuta. 


\section{References}

Mohideen, S., Sasikala, E., \& Gopal, V. 2002. Pharmacognostic studies on Sida acuta burm. f. Ancient science of life, 22(1): 57-66

Gamble, J. S. and Fischer, C. E. C., 1935. The flora of the presidency of Madras, Adlard and Son. Ltd. London.

Sreedevi, C. D., Latha, P. G., Ancy, P., Suja, S. R., Shyamal, S., Shine, V.J., and Rajasekharan, $\quad$ S. 2009. Hepatoprotective studies on Sida acuta Burm. f. y, 124(2): 171-175.

Tcheghebe, O. T., Seukep, A. J., and Tatong, F. N. 2017. Ethnomedicinal uses, phytochemical and pharmacological profiles, and toxicity of Sida acuta Burm. f.: A review article. The Pharma Innovation, 6(6, Part A), 1.

Mshana N. R., Abbiw D. K., Addae-Mensah I., Adjanouhoun E., Ahyi M.R.A. 2000, Traditional medicine and Pharmacopoeia contribution to the revision of ethnobotanical and floristic studies in Ghana.1st Edn, OAU/STRC, Accra.

Ramachandran, V. S., and Nair, N. C. 1981. Ethnobotanical observations on irulars of Tamil Nadu (India). J Econ Taxon Bot, 2:183-190.

Nadkarni, K. M. 1976. Indian materia medica: With ayurvedic, unani-tibbi, siddha, allopathic, homeopathic, naturopathic and home remedies, appendices and indexes-Vol. 2 (Vol. 2, No. na). Ramdas Bhatkal, Popular Prakashan Private Ltd.

Saraswathy, A., Susan, T., Gnana, R.R., Govindarajan, S., and Kundu, A.B. 1998. Chemical investigation of Sida acuta Burm. Bull Med Eth Bot Res, 19: 176-180.

Silja, V. P., Varma, K. S., and Mohanan, K. V. 2008. Ethnomedicinal plant knowledge of the Mullu kuruma tribe of Wayanad district, Kerala.

Holdsworth, D. K. 1974. phytochemical survey of medicinal plants of the D'entrecasteaux Islands, Papua. Sci New Guinea Univ Papua.

Khare, M., Srivastava, S. K., and Singh, A. K. 2002. Chemistry and pharmacology of genus Sida (Malvaceae)-a review. Journal of Medicinal and Aromatic Plant Sciences, 24(2): 430-440.

Kholkute, S. D., Munshi, S. R., Naik, S. D., \& Jathar, V.S. 1978. Antifertility activity of indigenous plants Sida carpinifolia Linn. \& Podocarpus brevifolius Stapf in female rats.

Ignacimuthu, S., and Ayyanar, M. 2006. Ethnobotanical investigations among tribes in Madurai district of Tamil Nadu (India). Journal of Ethnobiology and Ethnomedicine, 2(1): 1-7.

Jain, S. K. 1991. Dictionary of Indian folk medicine and ethnobotany (No. $581.634 \mathrm{~J} 3)$.

Barrett, B. (1994). Medicinal plants of Nicaragua's Atlantic coast. Economic botany, 48(1): 8-20.

Coe, F. G., \& Anderson, G.J. 1996. Screening of medicinal plants used by the Garifuna of Eastern Nicaragua for bioactive compounds. Journal of Ethnopharmacology, 53(1): 29-50.

Caceres, A., Giron, L. M., and Martínez, A. M. 1987. Diuretic activity of plants used for the treatment of urinary ailments in Guatemala. Journal of Ethnopharmacology, 19(3), 233-245.

Otero, R., Nunez, V., Jiménez, S. L., Fonnegra, R., Osorio, R. G., Garcia, M. E., and Diaz, A. 2000. Snakebites and ethnobotany in the northwest region of Colombia: Part II: neutralization of lethal and enzymatic effects of Bothrops atrox venom. Journal of Ethnopharmacology, 71(3), 505-511. 
Trivedi, H. B., and Vediya, S. D. 2013. Removal of fluoride from drinking water with the help of Sida acuta Burm f. International Journal of Pharmacy \& Life Sciences, 4(8).

Olivier, T. T., Francis, N. T., Armel, S., Jackson, K. J., and Justin, N. 2016. Ethnobotanic survey of medicinal plants used for malaria therapy in western Cameroon. Journal of Medicinal Plants, 4(3): 248-258.

Jayashree, M, Wesely, E. G. 2019. Studies on fungi associated with stored grains of Sorghum. International Journal of Research and Analytical Reviews, 6(1):476-478.

Osunlaja, S. O. 1990. Effect of organic soil amendments on the incidence of stalk rot of maize. Plant and soil, 127(2): 237-241.

Alka, J., Padma, K., and Chitra, J. 2012. Antifungal activity of flavonoids of Sida acuta Burm f. against Candida albicans. Int J Drug Dev Res, 4(3): 926.

Akilandeswari, S., Senthamarai, R., Valarmathi, R., Shanthi, S., and Prema, S. 2010. Screening of gastric antiulcer activity of Sida acuta burm. International Journal of PharmTech Research, 2(2): 1644-1648.

Ezeabara, C. A., \& Egenti, M O. 2018. Phytochemical and antimicrobial investigations on various parts of Sida acuta Burm. f. Journal of Ayurvedic and Herbal Medicine, 4(2): 71-75.

Karimi, E., and Jaafar, H. Z. 2011. HPLC and GC-MS determination of bioactive compounds in microwave obtained extracts of three varieties of Labisia pumila Benth. Molecules, 16(8): 67916805.

Gomathi, D., Kalaiselvi, M., Ravikumar, G., Devaki, K., and Uma, C. 2015. GCMS analysis of bioactive compounds from the whole plant ethanolic extract of Evolvulus alsinoides (L.) L. Journal of food science and technology, 52(2): 1212-1217.

Jose, G. S., and Radhamany, P M. 2013. In vitro antioxidant activities, total phenolics and flavonoid of wild edible mushroom

Macrolepiota mastoidea(fr.) Singer. Int. J. Pharm. Pharm. Sci, 5: 161-166.

Prakash, A., Varma, R. K., and Ghosal, S. 1981. Alkaloid constituents of Sida acuta, S. humilis, S. rhombifolia and $S$. spinosa. Planta medica, 43(12): 384388.

Karou, D., Savadogo, A., Canini, A., Yameogo, S., Montesano, C., Simpore, J., and Traore, A. S.2005. Antibacterial activity of alkaloids from Sida acuta. African journal of biotechnology, 4(12).

Konate, K., Souza, A., Coulibaly, A. Y., Meda, N. T., Kiendrebeogo, M., Lamien-Meda, A., and Nacoulma, O. G. 2010. In vitro antioxidant, lipoxygenase and xanthine oxidase inhibitory activities of fractions from Cienfuegosia digitata Cav., Sida alba L. and Sida acuta Burn f.(Malvaceae). Pakistan journal of biological sciences: PJBS, 13(22): 1092-1098.

Nwankpa, P., Chukwuemeka, O. G., Uloneme, G. C., Etteh, C. C., Ugwuezumba, P., \& Nwosu, D. 2015. Phyto-nutrient composition and antioxidative potential of ethanolic leaf extract of Sida acuta in wistar albino rats. African Journal of Biotechnology, 14(49): 3264-3269.

Muneeswari P., Bhaskaran S. K., Poornima K. 2019. Identification of active pharmaceuticals of Sida acuta Burm. f. leaves using GC-MS and HPTLC fingerprinting. Int. J. Pharm. Sci. Res., 10(3):1194-207.

Obah, I. E., Akerele, J. O., and Obasuyi, O. 2007. Antimicrobial activity of the 
ethanol extract of the aerial parts of Sida acuta burm. f.(malvaceae). Tropical Journal of Pharmaceutical Research, 6(4): 809-813.

Iroha, I. R., Amadi, E. S., Nwuzo, A. C., and Afiukwa, F. N. 2009. Evaluation of the antibacterial activity of extracts of Sida acuta against clinical isolates of Staphylococcus aureus isolated from human immunodeficiency virus/acquired immunodeficiency syndrome patients. Research Journal of Pharmacology, 3(2): 22-25.

Kannan, R. R., and Vincent, S. G. P. 2012. Cynodon dactylon and Sida acuta extracts impact on the function of the cardiovascular system in zebrafish embryos. Journal of biomedical research, 26(2): 90-97.
Malairajan, P., Gopalakrishnan, G., Narasimhan, S., and Veni, K. 2006. Antiulcer Activity of Sida acuta Burm. Natural Product Sciences, 12(3): 150152.

Arab, A., Akbarian, S. A., Ghiyasvand, R., and Miraghajani, M. 2016. The effects of conjugated linoleic acids on breast cancer: A systematic review. Advanced biomedical research, 5 .

Han, S., Jiao, J., Xu, J., Zimmermann, D., Actis-Goretta, L., Guan, L., and Qin, L. 2016. Effects of plant stanol or sterol-enriched diets on lipid profiles in patients treated with statins: systematic review and meta-analysis. Scientific reports, 6(1): 1-9.

\section{How to cite this article:}

Nalini, T. J., E. Keshamma, H. N. Ramesh Babu, N. Rajeshwari and Sridhar, B. T. 2021. GCMS Identification of Stem Extract of Sida acuta (Burm.f). Int.J.Curr.Microbiol.App.Sci. 10(05): 452-462. doi: https://doi.org/10.20546/ijcmas.2021.1005.053 